\title{
Catalyst Bed Instability within the USFE H2O2/JP-8 Rocket Engine
}

\author{
Curtis W. Johnson ${ }^{\sharp}$ \\ Sierra Engineering, Inc. \\ Carson City, NV \\ William Anderson \\ NASA MSFC \\ MSFC, AL \\ and \\ Robert Ross \\ Orbital Sciences Corp. \\ Chandler, AZ
}

\begin{abstract}
Orbital Sciences Corporation has been awarded a contract by NASA's Marshall Space Flight Center, in cooperation with the U.S. Air Force Research Laboratory's Military Space Plane Technology Program Office, for the Upper Stage Flight Experiment (USFE) program. Orbital is designing, developing, and will flight test a new low-cost, $10,000 \mathrm{lbf}$ hydrogen peroxide/ JP-8 pressure fed liquid rocket.
\end{abstract}

During combustion chamber tests at NASA Stennis Space Center (SSC) of the USFE engine, the catalyst bed showed a low frequency instability occurring as the $\mathrm{H} 2 \mathrm{O} 2$ flow reached about $1 / 3$ its design rate. This paper reviews the USFE catalyst bed and combustion chamber and its operation, then discusses the dynamics of the instability. Next the paper describes the dynamic computer model used to recreate the instability. The model was correlated to the SSC test data, and used to investigate possible solutions to the problem. The combustion chamber configuration which solved the instability is shown, and the subsequent stable operation presented.

\section{Introduction}

Orbital Sciences Corporation (Orbital) has been awarded a contract by NASA's Marshall Space Flight Center, in cooperation with the U.S. Air Force Research Laboratory, for the Upper Stage Flight Experiment (USFE) program. Orbital is designing and qualifying a new low-cost, liquid-fueled upper stage rocket engine as part of USFE. Orbital is also integrating the engine into the third stage of a new U.S. Air Force flight test vehicle capable of both suborbital and space missions.

The Orbital engine is a $10,000 \mathrm{lbf}$ pressure-fed liquid rocket engine that utilizes hydrogen peroxide $\left(\mathrm{H}_{2} \mathrm{O}_{2}\right)$ and JP-8 kerosene as propellants. Specifications for the USFE engine are listed in Table 1 . The engine utilizes a catalyst bed to decompose all the $\mathrm{H}_{2} \mathrm{O}_{2}$ into hot $\mathrm{H}_{2} \mathrm{O}$ and $\mathrm{O}_{2}$; the JP-8 is then burnt with the decomposed $\mathrm{H}_{2} \mathrm{O}_{2}$ in the main combustion chamber. A sketch of the instrumented heat-sink hardware that was tested at NASA Stennis Space Center is shown in Figure 1. An ablative chamber was also tested.

Initial tests of the catalyst bed identified a low frequency pressure instability as the $\mathrm{H}_{2} \mathrm{O}_{2}$ flow reached about $1 / 3$ of the design value. A plot of the pressure downstream of the catalyst bed as a function of time is included as Figure 2. At the beginning of this test the $\mathrm{H}_{2} \mathrm{O}_{2}$ flowrate is about $6 \mathrm{lbm} / \mathrm{s}$ (time $=12 \mathrm{sec}$ ), then at 20 seconds the flow is ramped up at a rate of about $0.4 \mathrm{lbm} / \mathrm{s}^{2}$. About 26 seconds into this test the device develops a slightly-amplified, low-amplitude $18 \mathrm{~Hz}$ pressure oscillation throughout the system that grows linearly until about 30 seconds, when it goes nonlinear with the same frequence. The $\mathrm{H}_{2} \mathrm{O}_{2}$ flowrate is approximately $12 \mathrm{lbm} / \mathrm{s}$ when the instability is triggered. The instability was shown to be repeatable, always being triggered when the $\mathrm{H}_{2} \mathrm{O}_{2}$ flowrate reached $12 \mathrm{lbm} / \mathrm{s}$.

\footnotetext{
"Member AIAA

${ }^{5}$ Member AIAA

Copyright $\odot 2000$ by Sierra Engineering, Inc. Published by American Institute of Aeronautics and Astronautics, Inc. with permission
} 
A recovery program was initiated to investigate the instability and develop a scheme to eliminate it. A dynamic system model was created that could capture the physics of the instability. The model was correlated to the test data, and the results were used to investigate solutions to the instability. This paper describes the modeling effort.

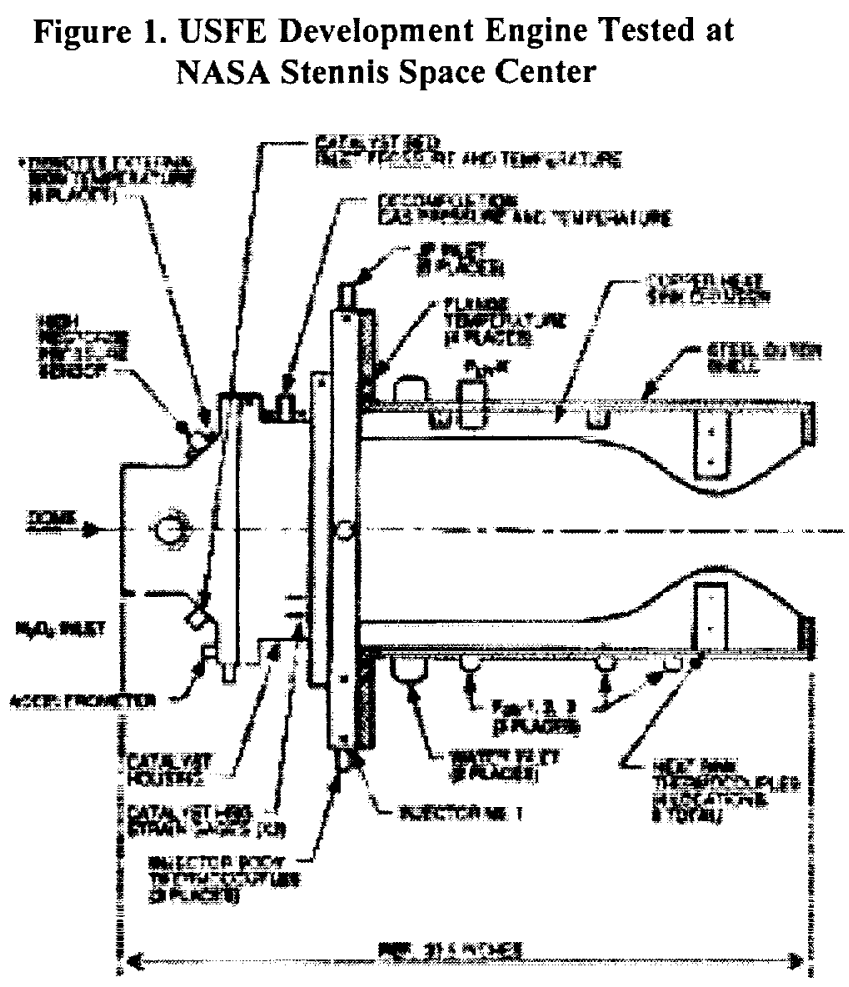

Table 1. 10Klbf Engine Design Parameters

\begin{tabular}{|l|l|}
\hline Thrust (vacuum) & $9,480 \mathrm{lbf}$ \\
\hline Chamber Pressure & $485 \mathrm{psia}$ \\
\hline Propellants & $90 \% \mathrm{H}_{2} \mathrm{O}_{2} / \mathrm{JP}-8$ \\
\hline Oxidizer Flowrate & $30.2 \mathrm{lbm} / \mathrm{s}$ \\
\hline Fuel Flowrate & $5.8 \mathrm{lbm} / \mathrm{s}$ \\
\hline Nozzle Expansion Ratio & 40 \\
\hline Specific Impulse & $264 \mathrm{lbf}-\mathrm{s} / \mathrm{lbm}$ \\
\hline
\end{tabular}

\section{Catalyst Bed Design and Operation}

The catalyst bed used in these tests incorporates a pack of solid silver and silver electroplated stainless steel screens. As hydrogen peroxide flows through the screens, it decomposes to produce hot $\mathrm{H}_{2} \mathrm{O}$ (steam) and $\mathrm{O}_{2}$. The primary design variable for the packed bed is the mass flux of the peroxide. This loading parameter, $G$, along with the distribution system and the inherent catalytic activity of the bed, determines the axial location of the decomposition, which is typically initiated at approximately $10 \%$ of the catalyst bed thickness. Thust, the residence time of the $\mathrm{H}_{2} \mathrm{O}_{2}$ determines where the decomposition occurs. To a first order approzimation, if the flow is doubled, the axial location of the decomposition plane in the catalyst bed also doubles. The bed design must include sufficient length so that the movement of the decomposition plane does not greatly effect the pressure drop across the bed.

It is important that the $\mathrm{H}_{2} \mathrm{O}_{2}$ flows evenly through the catalyst bed. If channeling occurs within the catalyst bed, the $\mathrm{H}_{2} \mathrm{O}_{2}$ decomposition sinks deeper in the bed, with the flow resistance depending strongly on the channel flowrate. Two operational problems can arise as a result of flow channeling:

- incomplete $\mathrm{H}_{2} \mathrm{O}_{2}$ decomposition occurs if the channel work its way completely through the bed;

- instability in the catalyst bed operation.

The original USFE catalyst bed showed physical signs of channeling.

\section{System Dynamic ROCETS Model}

A system dynamic model of the oxidizer side of the engine was constructed using the ROCETS computer code'. ROCETS (ROCket Engine Transient Simulation) is a steady-state/transient simulation computer model developed by NASA MSFC in the late 1980's. The code also includes a convenient balance operation that allows the users to vary engine parameters or physical inputs to meet predetermined operational goals. The code can run steady-state and transient analyses, and it is capable of linearizing a system to create a linear model of a single operating point.

Using the ROCETS code is a two-step process. The first step configures the model connectivity (plumbing) and selects the mathematical models used to analyze the system. The second step runs simulation. 
Figure 2. System Pressure Data Showing Instability

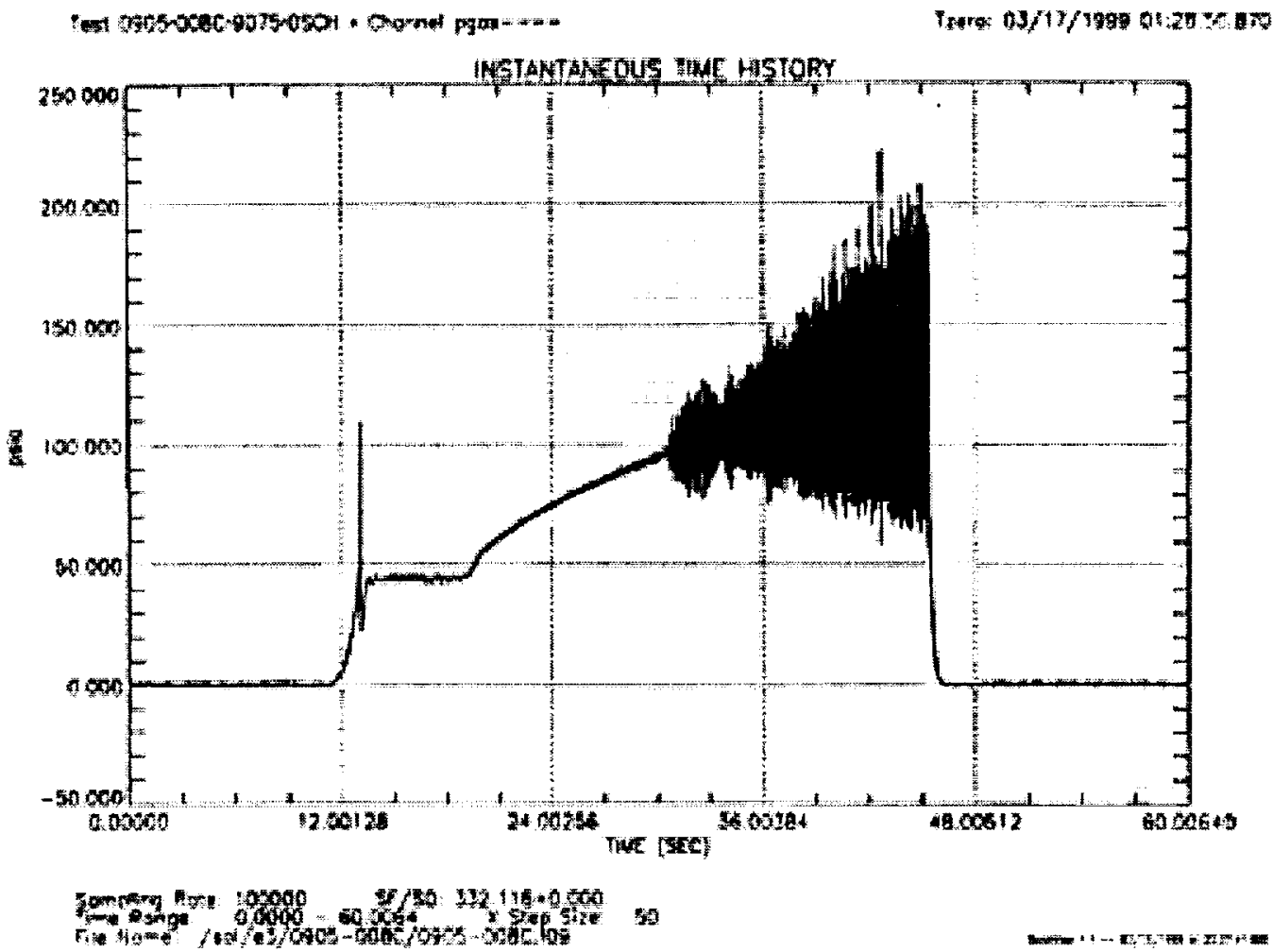

Figure 3. Block Diagram and ROCETS Analog of USFE Engine 


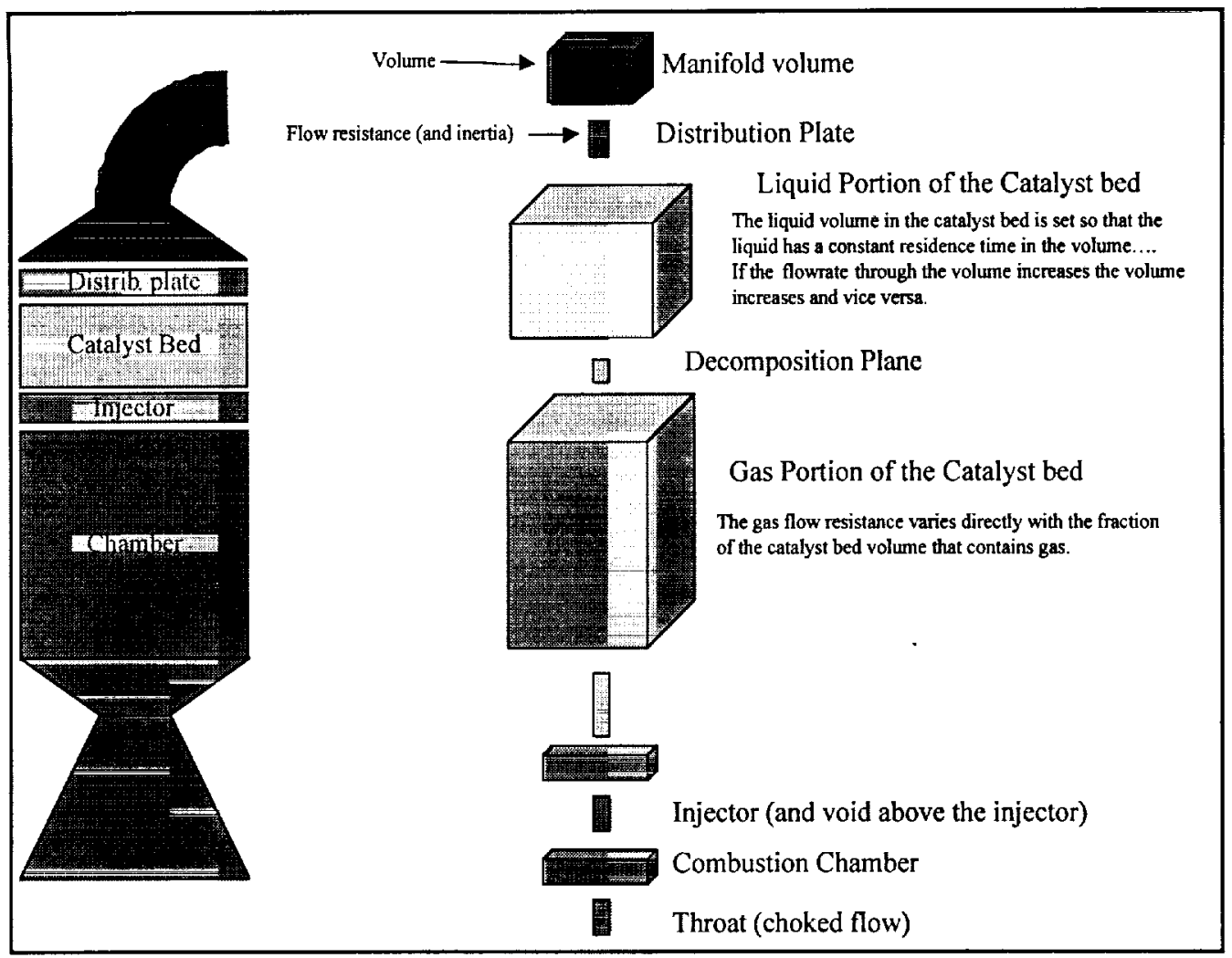

The basic ROCETS code does not include a dynamic model of a catalyst bed, however one has been developed as part of this investigation. The model assumes that a time dependent flow source feeds the catalyst bed's manifold. Test data suggest that the feed system is not actively involved in the instability, therefore it was not necessary to model the dynamics of the test facility. During typical simulations, the $\mathrm{H}_{2} \mathrm{O}_{2}$ flow was ramped with time to simulate test conditions, ending with a flowrate around $15 \mathrm{lbm} / \mathrm{s}$. The liquid $\mathrm{H}_{2} \mathrm{O}_{2}$ properties used for this analysis are listed in Table 2:

Table 2. $\quad \mathrm{H}_{2} \mathrm{O}_{2}$ Properties

\begin{tabular}{|l|l|}
\hline Density: & $0.0475 \mathrm{lbm} / \mathrm{in}^{3}$ \\
\hline Specific Heat: & $\begin{array}{l}0.764 \mathrm{BTU} / \mathrm{bm}- \\
\mathrm{R}\end{array}$ \\
\hline Bulk Modulus: & $320,000 \mathrm{psia}$ \\
\hline
\end{tabular}

The bulk modulus of the $\mathrm{H}_{2} \mathrm{O}_{2}$ shown in Table 2 was lowered to account for wall flexibility and a possible vapor bubble in the dome. Flow straightening hardware and instrumentation taps within the manifold were assumed to produce the vapor bubble. The bulk modulus dramatically decreases if a vapor bubble occupies even a small percentage of the manifold volume, and increasing the fluid compliance has an important that the effect on the model's natural frequency; therefore, it was important to account for this effect.

A small flow resistance downstream of the manifold feeds the first component of the catalyst bed model. The catalyst bed model is made of 5 components depicted in Figure 3:

1. the volume of the catalyst bed occupied by liquid,

2. the flow resistance of the liquid through the catalyst bed,

3. a thermal lag of the catalyst bed,

4. the volume of the catalyst bed occupied by gas,

5. the flow resistance of the gas through the catalyst bed.

The model assumes one-dimensional flow through the catalyst bed and a discrete plane of decomposition for the $\mathrm{H}_{2} \mathrm{O}_{2}$. The position of the decomposition plane within the catalyst bed varies, being determined such that the stay-time of liquid flowing through the bed is constant. The model assumes that the liquid immediately is decomposed to steam and oxygen once 
it meets the stay-time requirement. Specifically, the depth of the liquid in the catalyst bed is calculated by:

$$
\mathrm{h}=\frac{\overline{\dot{w}}}{\rho a} \hat{\mathrm{O}}
$$

Where $\mathrm{h}$ is the decomposition plane depth, $\overline{\dot{W}}$ is the average liquid flowrate $\frac{\dot{w}_{\text {in }}+\dot{w}_{\text {out }}}{2}$, is the density of the liquid, $a$ is the flow area of the catalyst bed, and is the required staytime of the liquid in the catalyst bed. During the analysis, the flow area $a$ is reduced to simulate channeling. Gas composition, derived from a one-dimensional equilibrium calculation for $85 \% \mathrm{H}_{2} \mathrm{O}_{2}$ and $15 \%$ water, is assumed to remain constant downstream from the decomposition plane.

The position of the decomposition plane is assumed to lag behind the calculated position due to thermal inertia. A simple first order timelag is included in the model to account for thermal inertia.

Once the decomposition plane depth is known, the volumes occupied by liquid and gas can be calculated. The flow resistance for the liquid portion of the catalyst bed is assumed to be sufficiently small, so as to not play a role in the system dynamics, consequently it is time invariant. However, the flow resistance of the gas through the catalyst bed is assumed to play an important role in the dynamics and varies linearly with the length of the gas portion of the catalyst bed, i.e. the distance from the decomposition plane to the catalyst bed exit.

The model contains a small volume downstream of the catalyst bed and upstream of the JP-8 injectors. This small volume was included in the model to permit the model to calculate pressure histories at a point that matched test data. Downstream of this volume the model incorporates another pressure drop to account for the JP-8 injector. The JP-8 circuit is not included in the current model, but it can be added at a later date. The final model segment is the main combustion chamber and a sonic throat.

\section{Simulation of the Instability}

After reviewing the engine configuration and the test data, it was postulated that the instability was caused due to channeling within the catalyst bed. The channeling would allow the decomposition plane to sink deep enough into the catalyst bed for the pressure drop across the catalyst bed to become very sensitive to changes in $\mathrm{H}_{2} \mathrm{O}_{2}$ flowrate. The result would be a channel first flooded with liquid, then as the liquid abruptly decomposed, the channel would be evacuated, leaving it open to flooding. This flood/evacuate cycle is the instability mechanism that the model was designed to evaluate.

The simulations were performed at a flowrate of 12 $\mathrm{lbm} / \mathrm{s}$, matching the flowrate of the hardware instability. The model assumes one-dimensional flow of the $\mathrm{H}_{2} \mathrm{O}_{2}$ through the circuit. For the onedimensional model to simulate channeling, it had to be assumed that $100 \%$ of the component flow went through the channel. Starting with the channel area equal to the full catalyst bed area, the channel area was decreased. As the channel area decreased, the decomposition plane dropped deeper into the catalyst bed, since the position of the decomposition plane is set by a constant stay-time of liquid. If the model had the proper dynamics, the flowrate into the catalyst bed should have become unstable, which it did. Once the instability was found, the manifold bulk modulus and the thermal time lag were varied until the instability showed the proper frequency and growth rate.

\section{Results}

There were two primary objectives behind the development of the model simulations. First was to simulate the instability so that its dynamics could be studied and the key contributors identified. The second goal was to identify ways of modifying the hardware and/or operation to eliminate the instability.

\section{Instability Simulation}

The catalyst bed model simulated the actual operating conditions of the hardware. The operation started with a constant $\mathrm{H}_{2} \mathrm{O}_{2}$ flowrate of $8 \mathrm{lbm} / \mathrm{s}$, which was held long enough to show steady state operation of the device ( $1 / 2$ second). After steady state was demonstrated the $\mathrm{H}_{2} \mathrm{O}_{2}$ flowrate increased at a rate of $2.4 \mathrm{lbm} / \mathrm{s}^{2}$ until a flowrate of $15 \mathrm{lbm} / \mathrm{s}$ was obtained. Figure 4 shows the mass flowrates for the simulation. It clearly shows that as the mass flowrate through the engine reached about $12.5 \mathrm{lbm} / \mathrm{s}$, the system pressure became unstable, producing severe oscillations throughout the system.

Test data for the gas pressure at the catalyst bed exit versus time are presented in Figure 2, while model predictions are shown in Figure 5. Comparing these two plots shows good agreement between the 
simulation and the hardware. The onset of the instability in the model occurs at the same flowrate as it does in the test hardware. The simulation model, like the test hardware, shows a $20 \mathrm{~Hz}$ oscillation. This frequency is insensitive to operating conditions.

One difference between the simulation and the actual test data is the simulation's inability to maintain pressure drop across the catalyst bed as the mass flow increases. This is due to the model's one-dimensional assumption, which requires all the $\mathrm{H}_{2} \mathrm{O}_{2}$ to flow through the channel. This is in contrast to the hardware where only allows a small percentage of the mass flow is expected to channel. Operating pressure appears to be a secondary contributor to the instability, so the mismatch with the test data is not of significant concern.

Figure 4. Model Mass Flow Results

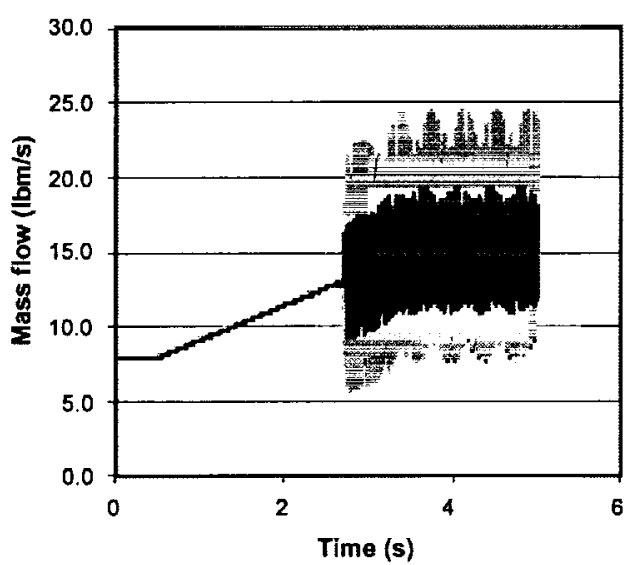

Figure 5. Model Pressure Results

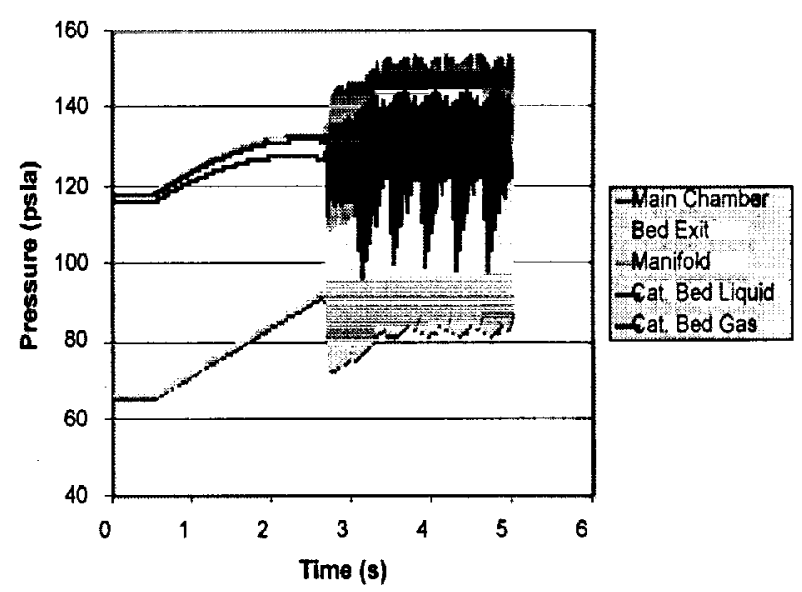

The primary cause of the instability is confirmed by examining the position of the decomposition plane within the catalyst bed. The position of the decomposition plane as a percentage of the total bed length for the simulations is plotted in Figure 6 . The figure shows that as the flowrate increases, the decomposition must sink deeper and deeper into the catalyst bed in order to maintain a constant residence - Catbed gas time for the liquid $\mathrm{H}_{2} \mathrm{O}_{2}$. The instability starts when -cat bed liquid the plane sinks to $80 \%$ of the total bed length. The Distribution plate $\mid$ model shows that the decomposition plane gets =chamberthroat pushed all the way through the catalyst bed during the oscillations, causing unreacted liquid $\mathrm{H}_{2} \mathrm{O}_{2}$ to be exhausted from the bed. Similar behavior was seen in the test videos which showed puffs of vapor exiting the engine during the instability.

Figure 6. Decomposition Plane as a Percentage of Total Bed Length

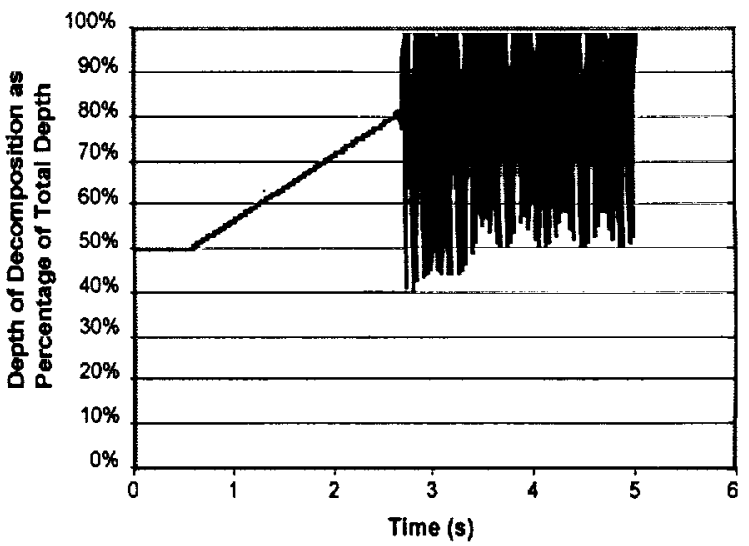


Figure 7 shows the dramatic change in the bed's flow resistance that accompanies the movement of the decomposition plane. This change in flow resistance occurs because the path length of the gas through the catalyst bed varies greatly. Since the liquid is much denser than the gas, it travels through the bed much more slowly, experiencing a very minor pressure drop.

\section{Figure 7. Catalyst Bed Gas Flow Resistance}

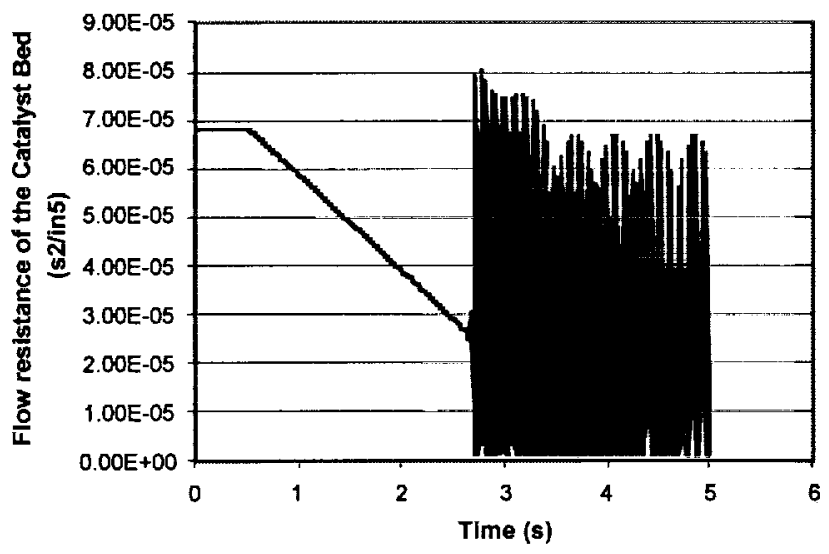

The phasing of the instability can be seen in plots of the mass flow (Figure 8) and pressure (Figure 9). The mass flow surges into the catalyst bed with a $90^{\circ}$ phase lead to the flow exiting the bed. This causes the pressure in the combustion chamber to experience a $180^{\circ}$ phase lag when compared to the manifold pressure, as can be identified in Figure 9. Actual waveforms of the simulation do not exactly match that of the test data, probably as a result of the onedimensional assumptions required by the model.

Figure 8. Mass Flow Phasing During Instability

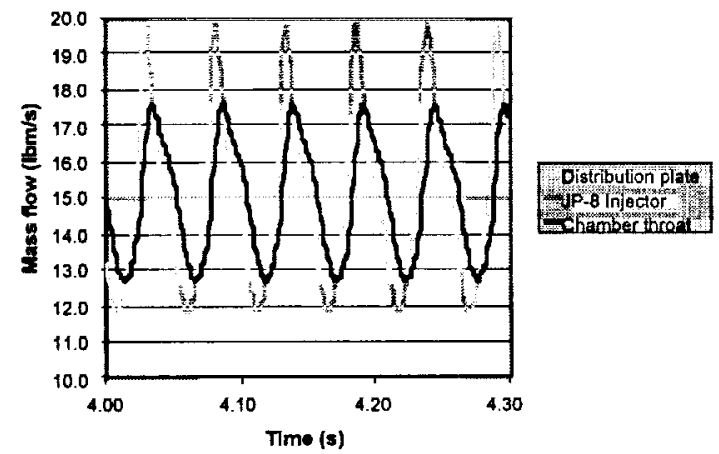

Figure 9. Pressure Phasing During Instability

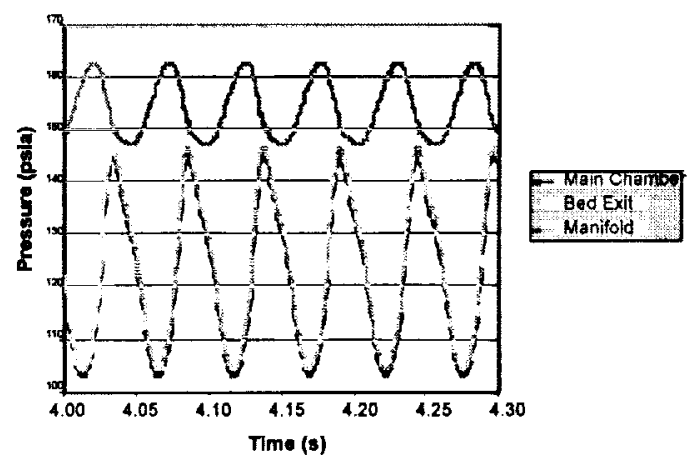

Three parameters were key in correlating model output to test data:

1. the channeled flow area of the $\mathrm{H}_{2} \mathrm{O}_{2}$ through the bed,

2. the bubble size (bulk modulus) of the fluid in the manifold dome,

3. the thermal time lag of the catalyst bed itself.

The channeled flow area correlated to 3 square inches, which calculates to be about $5 \%$ of the total flow area. The bulk modulus of the fluid needed to be dropped to 7000 psi to properly match the resonant frequency of the instability. The bulk modulus of $7000 \mathrm{psi}$ correlates to a vapor bubble taking up less than $2 \%$ of the manifold volume. As the percentage of the flow involved in channeling decreases, the required size of the vapor bubble decreases as well, so the actual size should be less than $2 \%$. Accounting for component and pipe wall flexibility would also reduce the bulk modulus. The thermal time lag required to correlate the model is determined to be 2.5 milliseconds. No effort has been made to compare this time lag to the components' physical configuration, e.g. screen mass and screen surface area.

\section{Solutions to the Instability}

Potential fixes that would eliminate the instability fall into three categories.

1. Alter the components to modify the natural frequencies of the system. These frequiencies must not couple throughout the desired operating range of the engine.

2. Add components, e.g. a gas accumulator, to shift or cancel natural frequencies over the desired engine operating range. 
3. Modifying the design so that the components perform as intended.

For this particular problem, option 3 is the only acceptable method. Although the system could be modified to prevent severe pressure oscillations, the channeling within the catalyst bed is so extreme that a large portion of the $\mathrm{H}_{2} \mathrm{O}_{2}$ would exit the bed as a liquid unless the channeling is prevented, or at least limited.

Figure 10 plots the $\mathrm{H}_{2} \mathrm{O}_{2}$ mass flow that would trigger an instability as a function of the percentage of the catalyst bed flow area involved in channeling. Since the analysis is one-dimensional, the percent channel area does not necessarily represent the actual flow area, but it does allow for a relative comparison. The plot implies the engine could operate stably with a large degree of channeling. Presumably a degree of channeling naturally occurs in these devices, thus the design guideline to decompose in the first $10 \%$ of the catalyst bed. If the channeling could be reduced, the catalyst bed could be designed with a fraction of the thickness.

Figure 10. $\mathrm{H}_{2} \mathrm{O}_{2}$ Mass Flowrate Required to Initiate Instability

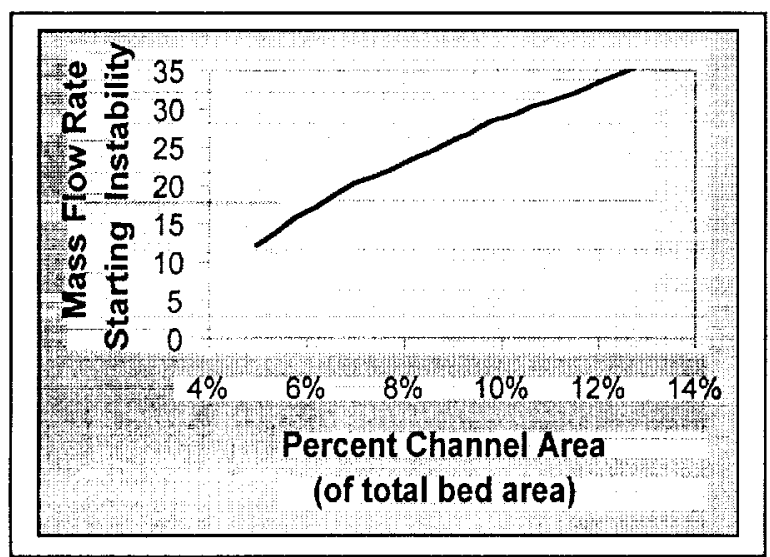

\section{Program Status}

The USFE combustor has met all the program requirements. The $C^{*}$ efficiency exceeds $97 \%$, and the life of the ablative chamber has been verified to exceed its 200 second requirement with sufficient margin.

After the successful completion of the engine developmental test series, the focus of the work has shifted toward a flight engine. The flight engine will be very similar to the current engine with an emphasis on weight reduction. Flight engine performance will be characterized in a pre-integrated stage test. An integrated stage ground test will be performed to demonstrate stage operation. Ground tests are scheduled for the first and fourth quarters of next year. The first flight is scheduled to take place in $\mathbf{2 0 0 2}$ from Kodiak Alaska.

\section{Conclusion}

A ROCETS model of the USFE engine catalyst bed has been completed. The model was developed to investigate a low-frequency instability experienced during mono-propellant-testing of the $\mathrm{H}_{2} \mathrm{O}_{2}$ circuit. The model is capable of simulating the instability and matches $\mathrm{H}_{2} \mathrm{O}_{2}$ flowrates at the instability onset as well as frequency of the oscillations.

The model suggests that the instability was caused by the hydrogen peroxide decomposition plane sinking deep into the catalyst bed, probably due to severe channeling. As the decomposition plane sinks into the catalyst bed, the $\mathrm{H}_{2} \mathrm{O}_{2}$ flowrate becomes very sensitive to the decomposition plane position. At $\mathrm{H}_{2} \mathrm{O}_{2}$ flowrates of about $12 \mathrm{lbm} / \mathrm{s}$ the decomposition matches a resonant frequency of the feed system and the device becomes unstable. Several design modifications to fix the problem have been indentified.

\section{References}

1) ROCETS User's Manual, United Technologies, Pratt and Whitney Government Engine business, West Palm Beach, FL, 31 August 1992 